\title{
Parlamentarische Mitwirkung in Angelegenheiten der Europäischen Union
}

Die Parlamente Deutschlands und Polens im europäischen Verfassungsverbund

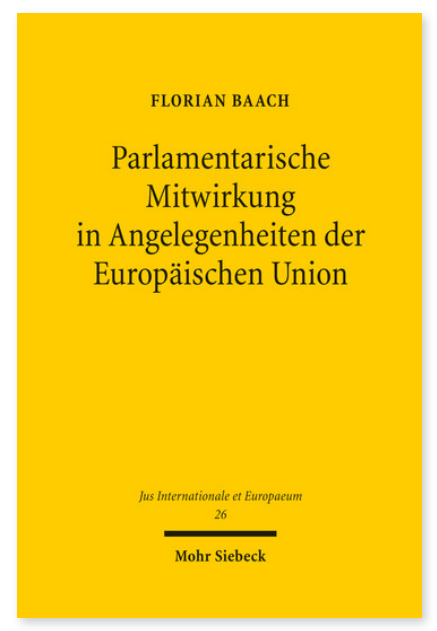

2008. XVI, 294 Seiten. JusIntEu 26

ISBN 978-3-16-151165-3

DOI 10.1628/978-3-16-151165-3

eBook PDF 74,00€

ISBN 978-3-16-149800-8

fadengeheftete Broschur 74,00€
Seit der Debatte um den Vertrag von Maastricht ist die Rolle der mitgliedstaatlichen Parlamente ein ständig wiederkehrender Topos in der Diskussion um die Verbesserung der demokratischen Legitimation der Europäischen Integration. Nach dem bekannten Diktum des Bundesverfassungsgerichts im Maastricht-Urteil sind sie es »zuvörderst «, die den Fortgang des Integrationsprozesses zu legitimieren haben. Der Vertrag von Lissabon räumt den nationalen Parlamenten erstmals unmittelbare Mitwirkungsrechte auf europäischer Ebene ein.

Florian Baach geht der Frage nach, wie groß der Legitimationsbeitrag der mitgliedstaatlichen Parlamente tatsächlich ausfällt. Er untersucht die Mitwirkung des deutschen und des polnischen Parlaments in Angelegenheiten der Europäischen Union, mit dem Schwerpunkt auf dem Deutschen Bundestag und dem Sejm der Republik Polen. Auf der Grundlage der Konzeption des Europäischen Verfassungsverbundes, bestehend aus den europäischen Verträgen und mitgliedstaatlichem Verfassungsrecht, entwickelt er zunächst Maßstäbe für das vom europäischen Demokratieprinzip jeweils geforderte Legitimationsniveau. Bei der anschließenden Untersuchung der parlamentarischen Mitwirkung bei der Primärrechtsetzung zeigt sich, daß die Parlamente zwar bei der Inkraftsetzung (ex post) primärrechtlicher Änderungsverträge eine starke Stellung innehaben, ihr legitimatorisches Potenzial aber bei der Ausarbeitung der Verträge (ex ante) trotz Konventsmethode bei weitem nicht ausgeschöpft wird. Im Rahmen der Vertragsausführung bleibt das Legitimationspotenzial von Bundestag und Sejm ebenfalls vielfach ungenutzt.

Florian Baach Geboren 1975; Studium der Rechtswissenschaft in München; 2003-2006 wissenschaftlicher Mitarbeiter an der Universität Greifswald; Beamter des Landes Berlin (wissenschaftlicher Dienst des Abgeordnetenhauses).
Jetzt bestellen:

https://mohrsiebeck.com/buch/parlamentarische-mitwirkung-in-angelegenheiten-der-europaeischen-union-9783161511653? no_cache=1

order@mohrsiebeck.com

Telefon: +49 (0)7071-923-17

Telefax: +49 (0)7071-51104 